\title{
Analisis Biaya Satuan (Unit Cost) Mahasiswa Berdasarkan Activity Based Costing Pada Politeknik "X” Di Balikpapan
}

\author{
Nur Vita Opu ${ }^{1)}$, Ida Suriana ${ }^{2)}$, Yogiana Mulyani ${ }^{3)}$ \\ Jurusan Tata Boga, Politeknik Negeri Balikpapan \\ Email : nur.vita@poltekba.ac.id \\ Email : ida.suriana@poltekba.ac.id
}

\begin{abstract}
This research is quantitative research. This research is aimed to design the Activity Based Costing and determine Unit Cost of educational services to students per course of study. This research was conducted at Balikpapan State Polytevhnic in 2014. The data collection was done by doing interview, observation and documentation. Unit Cost calculation result is a food and beverage department of Rp25.825.152, - per year, Electrical Engineering Program in Department of Industrial Electronics Engineering of Rp24.080.407, - per year. Department of Telecommunications of Rp24.080.407, - per year. Department of Computer Engineeringand Networks of Rp24.080.407, - per year, Civil Engineering Program of Rp24.795.028, - per year. MechanicalEngineering and Heavy Equipment Rp26.970.795, - per year.
\end{abstract}

Keywords : Unit Cost, Cost of Education, Activity Based Costing

\begin{abstract}
Abstrak
Penelitian ini merupakan penelitian kuantitatif. Penelitian ini bertujuan untuk merancang model pengalokasian berbasis aktivitas (Activity Based Costing) dan mengetahui biaya satuan (Unit Cost) layanan pendidikan kepada mahasiswa per program studi. Penelitian ini dilakukan di Politeknik X Tahun 2014. Pengumpulan data dilakukan dengan cara wawancara, observasi dan dokumentasi. Hasil perhitungan Unit Cost adalah Program Studi Tata Boga Rp25.825.152, - per tahun, Program Studi Teknik Elektro Jurusan Teknik Elektronika Industri Rp24.080.407,- per tahun. Jurusan Telekomunikasi Rp24.080.407,- per tahun. Jurusan Teknik Komputer dan Jaringan Rp24.080.407,- per tahun, Program Studi Teknik Sipil Rp24.795.028,- per tahun. Teknik Mesin dan Alat Berat Rp26.970.795,- pertahun.
\end{abstract}

Kata kunci : Biaya Satuan, Biaya Pendidikan, Biaya berbasis aktivitas

\section{Pendahuluan}

Ekonomi suatunegara dalam jumlah besar tergantung pada industri yang ada, khususnya sektor jasa seperti perusahaan asuransi, lembaga keuangan, pelayanan kesehatan, dan transportasi. Sebagian besar sektor korporasi lebih banyak bertualang ke bidang industri jasa untuk menciptakan persaingan, mereka diwajibkan untuk menyediakan layanan pelanggan berkualitas dengan biaya yang wajar (Krishnan, 2006).

Salah satu bentuk usaha pelayanan jasa adalah pendidikan.Pendidikan merupakan salah satu faktor dalam berkembangnya pembangunan suatu negara.Lembaga pendidikan merupakan salah satu lembaga yang memberikan pelayanan pendidikan sekaligus bertindak sebagai Badan Penyelenggara yang menghasilkan lulusan yang berkualitas sesuai dengan tuntutan dunia kerja.Selain memberi pelayanan pendidikan, lembaga pendidikan juga mengemban tugas sosial, yaitu mengutamakan kepentingan masyarakat dan tidak berorientasi pada keuntungan.

Oleh karena itu lembaga pendidikan termasuk organisasi non profit.Lembaga pendidikan sebagai organisasi non profit 
sangat memerlukan informasi biaya.Tanpa informasi biaya, pihak manajemen tidak memiliki ukuran apakah masukan yang dikorbankan memiliki nilai ekonomis yang lebih rendah daripada nilai keluarannya, sehingga manajemen tidak memiliki informasi apakah kegiatan usahanya menghasilkan sisa hasil usaha atau tidak.Sisa hasil usaha ini sangat diperlukan untuk mengembangkan dan mempertahankan eksistensi dalam jangka panjang sebuah lembaga pendidikan tersebut. Begitu juga sebaliknya tanpa informasi biaya, tidak akan dapat diketahui akurasi didalam penetapan biaya penyelenggara pendidikan itu apakah terlalu mahal atau terlalu murah. Selain itu pula, pihak manajemen tidak memiliki dasar untuk mengalokasikan berbagai sumber ekonomi yang dikorbankan dalam menghasilkan sumber ekonomi yang lain.

Di tengah fenomena tersebut, akuntabilitas keuangan oleh organisasi non profit dan salah satunya lembaga pendidikan menjadi sebuah tuntutan.Upaya untuk menyampaikan kepada stakeholders (mahasiswa, orang tua mahasiswa, pemerintah ataupun badan penyelenggara) merupakan hal penting agar terjadi keseimbangan antara kepentingan pihak manajemen maupun stakeholders.Lembaga dapat mengkomunikasikan secara transparan dan terbatas atas biaya penyelenggaraan pendidikan, disatu sisi masyarakat dapat menilai sekaligus mengevaluasi kinerja keuangan lembaga tersebut. Sehingga, akuntabilitas keuangan Perhitungan Biaya dapat meningkatkan kepercayaan masyarakat terhadap penyelenggaraan pendidikan, yang akhirnya mampu mendorong kesadaran dan partisipasi yang lebihtinggi terhadap lembaga pendidikan.

Penyajian informasi biaya bisa dilaksanakan bila manajemen bisa mengidentifikasi biaya-biaya apa saja yang telah terjadi dalam melaksanakan aktivitasnya. Keterbatasan kemampuan pihak manajemen perguruan tinggi dalam penyajian informasi biaya bisa menyebabkan pengelolaan lembaga tersebut kurangprofesional yang dapat memberi dampak buruk inefisiensi dan inefektivitas. Hal ini merupakan sesuatu yang wajar karena komponen biaya dalam perguruan tinggi sangatlah beragam sehingga sangat sulit menetapkan biaya langsung yang berhubungan dengan jasa pendidikan. Selain itu tidak ada standar baku untuk menetapkan tarif biaya-biaya yang berhubungan dengan penyelenggaraan penyajian. Agar dapat melaksanakan usaha pokok perguruan tinggi secara efisien, efektif, produktif dan berkualitas perguruan tinggi memerlukan informasi biaya satuan atau unit cost.

Menurut Juanda (2004) Analisis biaya studi setiap mahasiswa (Unit cost analysis) merupakan variabel diterminan dalam mewujudkan akuntabilitas keuangan

lembaga pendidikan. Analisis unit cost memberi dasar formula lembaga dalam mengkalkulasi biaya pendidikan seorang mahasiswa selama mengikuti studi di lembaga tersebut. Kalkulasi unit cost harus mencakup seluruh aktivitas studi baik yang berhubungan langsung maupun tidak dengan mahasiswa. Unit costakanmenggambarkan secara rinci dan menyeluruh atas beban mahasiswa selama studi di lembaga pendidikan. Beban unit cost setiap mahasiswa tersebut, akan ditandingkan (matching) dengan subsidi pendidikan pemerintah, sumbangan (partisipasi) masyarakat, dan pendapatan lain-lain lembaga, sehingga dapat diketahui beban yang harus ditanggung oleh mahasiswa selama studi. Sehingga, unit costakan menjadi landasan akuntabilitas keuangan lembaga kepada publik dan menjadi dasar pengambilan keputusan untuk menciptakan aktivitas penambah nilai.

Penerapan biaya satuan atau unit cost di perguruan tinggi sangat diperlukan agar dapat memberikan gambaran bagi perguruan tinggi dalam menghitung 
penetapan biaya penyelenggaraan pendidikan yang sudah barang tentu akan berbeda dengan perguruan tinggi yang lain walaupun penyelenggaraan pendidikan yang sama. Sehingga dapat dijadikan dasar bagi perguruan tinggi dalam menetapkan biaya penyelenggaraan pendidikan yang harus ditanggung oleh mahasiswa.

Oleh karena itu, peneliti menggunakan perhitungan biaya satuan menggunakan model Activity Based Costing (ABC) untuk menentukan harga pokok kegiatan pelayanan pendidikan per mahasiswa per program studi di Politeknik $\mathrm{X}$ diKota Balikpapan. Diharapkan melalui perhitungan $\mathrm{ABC}$ costing ini dapat mengukur biaya layanan pendidikan secara akurat dengan melakukan penelusuran tidak hanya pada seluruh Mahasiswa di Perguruan Tinggi.Namun lebih kepada tiap unit Mahasiswa dari masing-masing Program Studi. Dalam konsep pembiayaan pendidikan ada dua hal penting yang perlu dikaji atau dianalisis, yaitu biaya pendidikan secara keseluruhan (Total cost) dan biaya satuan per mahasiswa (Unit cost). Dengan menganalisis biaya satuan memungkinkan untuk mengetahui efisiensi dalam penggunaan sumber-sumber di perguruan tinggi, keuntungan dari investasi pendidikan, dan pemerataan pengeluaran masyarakat dan pemerintah untuk pendidikan.

Berdasarkan pemaparan di atas, penulis tertarik untuk menganalisis biaya satuan (unit cost) mahasiswa yang ada di jenjang pendidikan tinggi yaitu Politeknik Dimana Politeknik memiliki banyak sekali keberagaman jurusan atau program Studi. Pendidikan yang akan berjalan dengan efektif dan efisien apabila perguruan tinggi dapat menghitung biaya per mahasiswa (unit cost) dengan akurat dan dapat menyajikan informasi biaya secara transparan, akuntabel dan valid terhadap biaya pendidikan yang terjadi di perguruan tinggi, dengan harapan digunakan pihak manapun yang berkepentingan dalam penyelenggaraan pendidikan. Masalah yang muncul adalah : Bagaimana mengidentifikasi dan merancang model perhitungan biaya layanan pendidikan berbasis aktivitas (ABC) tiap program studi di Politeknik X di Kota Balikpapan dan Berapa biaya satuan (unit cost) pelayanan pendidikan yang dihitung menggunakan metode Acticity Based Costing (ABC) per mahasiswa masingmasing program keahlian di Politeknik X Kota Balikpapan. Dan tujuan Penelitian sebagai barikut :Merancang model pengalokasian biaya berbasis aktivitas (Activity Based Costing) berdasarkan proses bisnis dan aktivitas teridentifikasi di Politeknik X Kota Balikpapan, dan Mengetahui besarnya biaya satuan (unit cost) layanan pendidikan per mahasiswa per program Studi di Politeknik X Kota Balikpapan.

Landasan Teori Biaya (cost) didefinisikan sebagai suatu sumber daya yang dikorbankan (sacrified) ataudilepaskan (forgone) untuk mencapai tujuan tertentu. Suatu biaya biasanya diukur dalam unit uang yang harus dikeluarkan dalam rangka mendapatkan barang/jasa.Dalam konteks pendidikan, Nanang Fattah mendefinisikan "Biaya pendidikan sebagai jumlah uang yang dihasilkan dan dibelanjakan untuk berbagai keperluan penyelenggaraan pendidikan. (Nanag Fattah : 2009) "Biaya merupakan salah satu aspek penunjang serta penentu dalam suatu proses pendidikan. Dimana hampir seluruh proses dalam penyelenggaraan pendidikan memerlukan biaya, mulai dari aktivitas inti pendidikan yaitu kegiatan belajar mengajar sampai kepada aktivitas penunjang seperti kegiatan UKM Mahasiswa, kedua-duanya memerlukan yang namanya biaya (Dedi Supriadi : 2003). Dedi Supriadi mengartikan biaya pendidikan sebagai semua jenis pengeluaran yang berkenaan dengan penyelenggaraan pendidikan, baik dalam bentuk uang maupun barang dan tenaga (yang dapat dihargai sebagai uang). 
Konsep biaya menurut Tilaar adalah "Biaya merupakan keseluruhan dana dan upaya yang diserahkan oleh masyarakat untuk mendapatkan pendidikan dan dalam kenyataan bahwa kegiatan pendidikan merupakan bentuk dari pelayanan masyarakat (Tilaar : 2009).

Petunjuk Teknis Perhitungan Biaya Operasional Perguruan Tinggi (BOPTN), menyebutkan bahwa "Biaya pendidikan didefinisikan sebagai nilai rupiahdari seluruh sumber daya (input) baik dalam bentuk barang (natura),pengorbanan peluang, maupun uang yang dikeluarkan untuk seluruhkegiatan pendidikan.

"Pengertian lain berkenaan dengan biaya pendidikan diungkapkan olehSyaiful Sagala bahwa "Biaya pendidikan adalah seluruh usaha yangdicurahkan oleh pemerintah dan masyarakat pendidikan berupa uangmaupun nonmoneter.

\section{a. Biaya Satuan (Unit Cost) Pendidikan}

Panduan Fasilitasi Penghitungan

Biaya Operasional Satuan Pendidikan (BOSP) dan Penyusunan Kebijakan (2008:9) menjelaskan bahwa biaya pendidikandiukur sebagai biaya satuan (unit cost) yaitu biaya pendidikan per tahun per mahasiswa danbiaya siklus (cycle cost) yaitu biaya yang dibutuhkan oleh setiap mahasiswa untukmenyelesaikan suatu jenjang pendidikan. Cycle cost adalah unit cost dikalikan denganwaktu (dalam tahun) yang dibutuhkan untuk menyelesaikan suatu jenjang pendidikan.Menurut Asrori Ardiansyah (2011), biaya satuan per mahasiswa merupakanukuran yang menggambarkan seberapa besar uang yang dialokasikan perguruan tinggi secaraefektif untuk kepentingan mahasiswa dalam menempuh pendidikan.

\section{b. Klasifikasi Biaya Pendidikan}

\section{Pada Panduan Fasilitasi}

Penghitungan Biaya Operasional Satuan Pendidikan (BOSP) dan Penyusunan Kebijakan (2008:9) disebutkan bahwa biaya satuan pendidikan dapat diklasifikasikan berdasarkan: (1) jenis input, (2) sifat penggunaan, (3) jenis penggunaan, (4) pihak yang menanggung, dan (5) sifat keberadaannya. Masingmasing klasifikasi dapat dijelaskan sebagai berikut.

1) Biaya Satuan Pendidikan Berdasarkan Jenis Input

Biaya satuan pendidikan berdasarkan jenis input dapat diklasifikasikan ke dalambiaya operasional dan biaya investasi.

a) Biaya operasional adalah biaya pendidikan yang habis dipakai dalam jangka waktu satu tahun atau kurang, atau biaya yang dikeluarkan berulang-ulang setiap tahunnya. Biaya operasional mencakup pengeluaran untuk: gaji dan tunjangan, barang-barang yang harus sering diganti dengan yang baru, beasiswa, biaya pelayanan kesejahteraan (kantin, transport, penginapan dan olahraga) pemeliharaan gedung dan peralatan, langganan bandwith (internet) serta biaya langganan daya/jasa seperti listrik, telepon, dan air tanah.

b) Biaya investasi adalah biaya pendidikan yang penggunaannya lebih dari satu tahun. Biaya investasi ini meliputi: pembelian tanah, pembangunan gedung perkantoran, pembangunan gedung layanan pendidikan, pembangunan gedung laboratorium, pengadaan peralatan laboratorium, pengadaan peralatan pembelajaran, pengadaan buku perpustakaan, pengembangan sumber daya manusia, perlengkapan pelajaran lain yang tahan lama, pembangunan asrama, pengadaan lahan pendidikan, dan sebagainya. 
b. Biaya Satuan Pendidikan Berdasarkan Sifat Penggunaan

Biaya satuan pendidikan dapat dibedakan antara biaya langsung (direct costs) dan biaya pendidikan tidak langsung (indirect costs).

1) Biaya langsung (direct costs) adalah biaya yang dikeluarkan untuk kebutuhan input yang langsung terkait dengan proses belajar mengajar. Biaya satuan pendidikan langsung ini mencakup pengeluaranpengeluaran, antara lain untuk: gaji dosen dan tenaga kependidikan lainnya; pembelian bahan praktek, peralatan dan perlengkapan belajar; dan pembangunan gedung untuk belajar.

2) Biaya tidak langsung (indirect costs) adalah biaya yang dikeluarkan untuk kegiatankegiatan yang tidak berkaitan langsung dengan proses belajar mengajar tetapi menunjang proses belajar mengajar tersebut. Biaya tidaklangsung ini, antara lain adalah: biaya overhead universitas, fakultas, lembaga, pemerintah pusat, dan pendapatan yang tidak jadi diterima oleh mahasiswa karena kuliah dan tidak bekerja (forgone earning).

c. Biaya Satuan Pendidikan Berdasarkan Jenis Penggunaan

Menurut jenis penggunaannya khususnya biaya operasional dapat dikelompokkan ke dalam biaya operasional personel dan biaya operasional bukan personel.

1) Biaya operasional personel adalah biaya yang dikeluarkan untuk kesejahteraan dan pengembangan personel. Personel dimaksud meliputi dosen dan tenaga kependidikan (laboran, pustakawan, tenaga administrasi), administrator meliputi pimpinan universitas, fakultas, lembaga, unit pelaksana teknis, dan lain-lain.

2) Biaya operasional bukan personel adalah biaya yang dikeluarkan untuk menyediakan segala bahan, peralatan, perlengkapan, serta sarana dan prasarana yang digunakan untuk proses pembelajaran, seperti buku, alat tulis, pemeliharaan gedung, daya dan jasa, dan lain-lain.

d. Biaya Satuan Pendidikan Berdasarkan Pihak yang Menanggung

Berdasarkan pihak yang menanggung, biaya pendidikan dapat digolongkan menjadi biaya pribadi (private unit costs), biaya satuan publik (public unit cost), dan biaya satuan sosial/total (social/total unit cost).

1) Biaya pribadi (private unit costs) adalah biaya yang ditanggung oleh orang tua (mahasiswa) per tahun. Biaya pribadi mencakup pengeluaran untuk sumbangan pendidikan, buku dan alat tulis, pakaian, akomodasi, transportasi, konsumsi, karyawisata, uang jajan, kursus, dan forgone earning, yaitu potensi penghasilan yang tidak jadi diterima karena mahasiswa tidak bekerja.

2) Biaya publik (public unit cost) adalah biaya yang ditanggung oleh pemerintah dan masyarakat, yang berarti keseluruhan biaya selain yang ditanggung oleh orangtua (mahasiswa) per tahun.

3) Biaya sosial (total) (social/total unit cost) adalah total biaya yang ditanggung pemerintah, orangtua (mahasiswa) dan 
masyarakat lain per tahun, atau sama dengan biaya pribadi ditambah dengan biaya publik.

e. Biaya Satuan Pendidikan Berdasarkan Keberadaannya

Biaya satuan pendidikan dapat dibedakan ke dalam biaya pendidikan faktual danbiaya pendidikan ideal.

1) Biaya pendidikan faktual adalah biaya-biaya yang senyatanya dikeluarkan dalam penyelenggaraan pendidikan.

2) Biaya pendidikan ideal adalah biaya-biaya satuan pendidikan yang semestinya dikeluarkan agar penyelenggaraan pendidikan dapat menghasilkan mutu pendidikan yang diinginkan.

\section{Metode Penelitian}

Metoda Penelitian yang dilakukanmenggunakan pendekatan kualitatif dan menggunakan metode analisis deskriptif. Metode analisis deskriptif dilakukan untuk memaparkan perhitungan biaya satuan per mahasiswa per program studi. Perhitungan dilakukan menggunakan model Activity Based Costing (ABC).Sumber data adalah subjek dari mana data dapat diperoleh. Terdapat 3 macam sumber data, yaitu:

a. Person, yaitu sumber data yang bisa memberikan data berupa jawaban lisan melalui wawancara atau jawaban tertulis melalui angket. Adapun sumber data yang berupa person dalam penelitian ini yakni Wakil Direktur II, Kasubag Umum dan Staf Keuangan, Pengelola Laporan Keuangan dan Pengelola BMN.

b. Place, yaitu sumber data yang menyajikan tampilan berupa keadaan diam dan bergerak. Sumber data ini berasal pada tempat penelitian yakni Politeknik X.

c. Paper, yaitu sumber data yang menyajikan tanda-tanda berupa huruf, angka, gambar, atau simbol-simbol lain. Sumber data ini meliputi dokumen Rencana Kegiatan dan Anggaran Kementrian / Lembaga (RKAKL) Tahun 2012/2013 dan Tahun 2013/2014, dokumen realisasi DIPA Tahun 2013 dan dokumen-dokumen lain yang dibutuhkan dalam penelitian ini.

Adapun dalam penelitian ini menggunakan sumber data seperti person dan paper untuk memperoleh data-data yang dibutuhkan dalam penelitian ini. Data dalam penelitian ini yakni:

a. Data Primer

Data primer diperoleh dari sumber data pertama yakni person dengan menggunakan prosedur dan teknik pengumpulan data melalui wawancara dan observasi.

b. Data Sekunder

Data sekunder diperoleh dari sumber data ketiga yakni paper dengan menggunakan teknik dokumentasi.

\subsection{Populasi dan Sampel Penelitian}

Populasi dalam penelitian ini adalah seluruh civitas akademika yaitu Direktur, wakil Direktur, tenaga kependidikan dan mahasiswa. Dalam penelitian kualitatif menggunakan nonprobabilitas sampling dengan menggunakan teknik purposive sampling, yaitu menentukan sampel dengan pertimbangan tertentu yang dipandang dapat memberikan data secara maksimal. Adapun sampel dalam penelitian ini yakni Wakil Direktur II, Kasubag Umum dan Staf Keuangan, Pengelola Laporan Keuangan dan Pengelola BMN serta 4 (empat) program keahlian yakni Teknik Mesin, Teknik elektronika, Teknik Sipil dan Tata Boga.

\subsection{Teknik Pengumpulan Data}

Adapun teknik pengumpulan data dalam penelitian ini yaitu :

a. Wawancara 
Wawancara adalah alat pengumpul informasi dengan cara mengajukan sejumlah pertanyaan secara lisan untuk dijawab secara lisan pula. Ciri utama dari wawancara adalah adanya kontak langsung dengan tatap muka antara pencari informasi (interviewer) dan sumber informasi (interviewee). Wawancara dilakukan secara formal. Metode wawancara digunakan untuk mengumpulkan data mengenai manajemen keuangan institusi, pelaksanaan penyusunan Rencana Kegiatan dan Anggaran institusi, aktivitas-aktivitas yang terjadi di institusi, dan system pelaporan yang digunakan oleh institusi. Adapun sumber informasi dari wawancara yang dilakukan adalah Wakil Direktur II, Kasubag Umum dan Staf Keuangan, Pengelola Laporan Keuangan dan Pengelola BMN

\section{b. Observasi}

Observasi seseorang untuk menggunakan pengamatannya melalui hasil kerja pancaindra mata serta dibantu dengan pancaindra lainnya. Observasi dilakukan dalam rangka cross-check data dan agar memperoleh gambaran kondisi sesungguhnya. Dan untuk mengetahui aktivitas-aktivitas yang dilaksanakan pada proses manajerial, proses utama dan proses pendukung sehingga dapat melakukan mapping terhadap cost component yang relevan bagi perhitungan unit cost program studi Politeknik X

\section{c. Dokumentasi}

Dokumentasi dari asal katanya dokumen yang artinya barang-barang tertulis. Di dalam melaksanakan metode dokumentasi, peneliti menyelidiki bendabenda tertulis seperti buku-buku, majalah, dokumen, peraturan-peraturan, notulen rapat, catatan harian, dan sebagainya.Penulis mengumpulkan datadata berupa dokumen institusi seperti data mahasiswa, pendidik dan tenagakependidikan, data sarana prasarana,
RKAKL/DIPA, Realisasi RKAKL, Laporan SAKPA, BMN DLL.

\subsection{Teknik Analisis Data}

Teknik analisis data yang digunakan sesuai dengan tujuan penelitian ini yakni mendapatkan nominal biaya pendidikan per mahasiswa per bulan berdasarkan perhitungan dengan pendekatan Activity Based Costing (ABC). Instrumen yang digunakan dalam penelitian ini adalah data keuangan dan non keuangan yang dirumuskan untuk mencapai tahapan penelitian dan analisa sebagai berikut:

a. Telaah Aktivitas

1) Mengidentifikasi semua aktivitas yang terjadi di Politeknik X .

2) Mengidentifikasi semua sumber daya (resources) yang dikonsumsi oleh institusi, baik yang berupa uang (dana anggaran), tenaga kerja, mesin/peralatan dan lainnya.

3) Mengidentifikasi jumlah orang, jumlah peralatan dan jumlah perlengkapan, besar gaji, honor dan insentif dan lainnya (resources driver) untuk setiap komponen dihubungkan dengan aktivitas.

4) Selanjutnya dari proses tersebut akan ditentukan cost driver yang telah disiapkan yang relevan dengan aktivitas yang telah ditentukan, misalnya untuk aktivitas umum seperti listrik, telepon menggunakan driver jumlah.

5) Membebankan biaya ke aktivitas secara penuh sesuai dengan banyaknya resources yang dikonsumsi melalui cost driver yang telah dipilih dan relevan dengan aktivitas proses utama.

b. Telaah Cost Object

1) Mengidentifikasi Cost Object. 
2) Mengidentifikasi Activity Driver, misalnya jam penggunaan ruang, jumlah mahasiswa, luas gedung dan ruangan, pemakaian daya dan jasa untuk setiap aktivitas yang menyerap biaya penuh untuk menghubungkan aktivitas ke Cost Object yang dikonsumsinya.

3) Membebankan biaya ke Cost Object secara penuh sesuai besarnya biaya yang dikonsumsi melalui Activity Driver di Program Keahlian.

c. Tahap Perancangan Model

1) dentifikasi proses bisnis Politeknik X, meliputi proses manajerial, proses utama dan proses pendukung.

2) Review data keuangan Politeknik X meliputi Laporan Keuangan, RKAKL, data Realisasi RKAKL, DIPA 2013 2014 untuk mengetahui mata anggaran yang ada, serta batasan penggunaannya.

3) Mengidentifikasi dan membuat definisi aktivitas-aktivitas utama yang dilakukan oleh institusi ke dalam activity dictionary atau rincian aktivitas yang mendefinisikan keseluruhan aktivitas yang mencerminkan proses manajerial, utama dan pendukungnya.

4) Mengidentifikasi dan menetapkan Cost Object, Direct LaborCost,Direct Material Cost dan Overhead Cost. Penetapan dimaksudkan untuk menyamakan persepsi pembaca dan menjelaskan acuan istilah tersebut dalam penelitian ini.

5) Identifikasi Expense Category, Cost Driver, dan Cost Component. Penyusunan hirarki alokasi Activity Overhead Cost pada tiap Program Studi. Hal ini dimaksudkan untuk menentukan/mengestimasi proporsi biaya yang diserap, yaitu melalui proporsi yang besarnya ditentukan oleh cost driver yang telah diidentifikasi.

\section{Hasil dan Pembahasan}

Perhitungan biaya pendidikan yang dilakukan oleh peneliti adalah dengan melakukan perhitungan dengan senyatanya. Sebagai sebuah organisasi yang termasuk dalam organisasi non-profit dalam menggunakan model ABC menghitung pengeluaran berdasarakan kegiatan serta alokasi yang digunakan dalam melaksanakan sebuah kegiatan yang ada di Politeknik X.

Langkah awal dalam menggunakan metode ABC adalah dengan mengidentifikasi kegiatan-kegitan yang ada dilingkup Politeknik $\mathrm{X}$. Berikut adalah aktivitas operasional/Rutin yang dilakukan oleh politeknik X:

Tabel 1 Aktivitas Operasional/Rutin Dipoliteknik X

\begin{tabular}{|c|c|c|}
\hline No & Aktivitas & Deskripsi \\
\hline 1 & $\begin{array}{l}\text { Registrasi } \\
\text { Mahasiswa } \\
\text { baru }\end{array}$ & $\begin{array}{l}\text { Kegiatan yang } \\
\text { dilakukan untuk } \\
\text { menerima calon } \\
\text { mahasiswa baru }\end{array}$ \\
\hline 2 & $\begin{array}{l}\text { Penerimaan } \\
\text { mahasiswa } \\
\text { baru }\end{array}$ & $\begin{array}{l}\text { Calon mahasiswa } \\
\text { yang telah lulus } \\
\text { seleksi akan } \\
\text { menjadi } \\
\text { mahasiswa baru }\end{array}$ \\
\hline 3 & $\begin{array}{l}\text { PKK } \\
\text { (Pengenalan } \\
\text { Kehidupan } \\
\text { Kampus }\end{array}$ & $\begin{array}{l}\text { Masa orientasi } \\
\text { mahasiswa baru } \\
\text { untuk lebih } \\
\text { mengenal } \\
\text { kehidupan kampus }\end{array}$ \\
\hline 4 & Tes psikologi & \\
\hline 5 & $\begin{array}{l}\text { Registrasi } \\
\text { Semester 1-6 }\end{array}$ & $\begin{array}{l}\text { Registrasi sebelum } \\
\text { kegiatan } \\
\text { perkuliahn dimulai } \\
\text { untuk melihat } \\
\text { jumlah mahasiwa }\end{array}$ \\
\hline
\end{tabular}




\begin{tabular}{|c|c|c|}
\hline & & $\begin{array}{l}\text { per semester yang } \\
\text { aktif untuk } \\
\text { mengikuti } \\
\text { kegiatan } \\
\text { perkuliahan }\end{array}$ \\
\hline 6 & $\begin{array}{l}\text { Kuliah } \\
\text { Semester 1-6 }\end{array}$ & $\begin{array}{l}\text { Proses belajar } \\
\text { mengajar yang } \\
\text { dilaksanakan } \\
\text { disetiap semester }\end{array}$ \\
\hline 7 & Praktikum & $\begin{array}{l}\text { Salah satu proses } \\
\text { atau kegiatan } \\
\text { belajar mengajar }\end{array}$ \\
\hline 8 & $\begin{array}{l}\text { Praktikum } \\
\text { Komputer }\end{array}$ & $\begin{array}{l}\text { Salah satu proses } \\
\text { atau kegiatan } \\
\text { belajar mengajar }\end{array}$ \\
\hline 9 & $\begin{array}{l}\text { Pembimbing } \\
\text { Utama } \\
\text { Akademik per } \\
\text { mhs sd selesai }\end{array}$ & $\begin{array}{l}\text { Kegitan } \\
\text { bimbingan oleh } \\
\text { dosen wali kepada } \\
\text { mahasiswa wali }\end{array}$ \\
\hline 10 & $\begin{array}{l}\text { Pembuatan } \\
\text { soal per soal } \\
\text { baru }\end{array}$ & $\begin{array}{l}\text { Pembutan soal } \\
\text { ujian }\end{array}$ \\
\hline 11 & $\begin{array}{l}\text { Pengawas } \\
\text { ujian per } \\
\text { pengawas }\end{array}$ & $\begin{array}{l}\text { Pengawasan } \\
\text { kegiatan ujian }\end{array}$ \\
\hline 12 & $\begin{array}{l}\text { Pembekalan } \\
\text { PKL }\end{array}$ & $\begin{array}{l}\text { Persiapan dengan } \\
\text { pemberian materi } \\
\text { kepada mahasiswa } \\
\text { sebelum Praktek } \\
\text { Kerja Lapangan }\end{array}$ \\
\hline 13 & $\begin{array}{l}\text { Pelaksanaan } \\
\text { PKL }\end{array}$ & $\begin{array}{l}\text { Praktek Kerja } \\
\text { Lapangan }\end{array}$ \\
\hline 14 & Monitoring & $\begin{array}{l}\text { Pemantauan } \\
\text { Dosen } \\
\text { Pembimbing } \\
\text { kepada mahasiswa } \\
\text { yang sedang } \\
\text { melaksanakan } \\
\text { PKL }\end{array}$ \\
\hline 15 & $\begin{array}{l}\text { Seminar Hasil } \\
\text { PKL }\end{array}$ & $\begin{array}{l}\text { Mahasiswa } \\
\text { memberikan } \\
\text { laporan PKL }\end{array}$ \\
\hline 20 & $\begin{array}{l}\text { Ujian } \\
\text { Kompetensi }\end{array}$ & $\begin{array}{l}\text { Pelaksanaan Ujian } \\
\text { Kompetensi }\end{array}$ \\
\hline 21 & Bimbingan TA & $\begin{array}{l}\text { Pembimbingan } \\
\text { oleh Dosen untuk } \\
\text { pembuatan Tugas } \\
\text { Akhir }\end{array}$ \\
\hline 22 & $\begin{array}{l}\text { Seminar } \\
\text { Proposal TA }\end{array}$ & $\begin{array}{l}\text { Pelaksanaan } \\
\text { Seminar Proposal }\end{array}$ \\
\hline
\end{tabular}

\begin{tabular}{|c|l|l|}
\hline 23 & Sidang TA & $\begin{array}{l}\text { Pelaksanaan Tugas } \\
\text { Akhir }\end{array}$ \\
\hline 24 & Test Toefl & $\begin{array}{l}\text { Pelaksanaan Tes } \\
\text { Toefl }\end{array}$ \\
\hline 25 & $\begin{array}{l}\text { Rapat } \\
\text { Yudisium }\end{array}$ & $\begin{array}{l}\text { Pelaksanaan Rapat } \\
\text { Yudisium }\end{array}$ \\
\hline 26 & $\begin{array}{l}\text { Upacara } \\
\text { Yudisium }\end{array}$ & $\begin{array}{l}\text { Pelaksanaan } \\
\text { Upacara Wisuda }\end{array}$ \\
\hline 27 & $\begin{array}{l}\text { Pendaftaran } \\
\text { wisuda }\end{array}$ & $\begin{array}{l}\text { Pendaftaran } \\
\text { peserta wisuda }\end{array}$ \\
\hline 28 & $\begin{array}{l}\text { Perlengkapan } \\
\text { Wisuda }\end{array}$ & $\begin{array}{l}\text { Pengambilan } \\
\text { Perlengkapan } \\
\text { Wisuda }\end{array}$ \\
\hline 29 & $\begin{array}{l}\text { Upacara } \\
\text { wisuda }\end{array}$ & $\begin{array}{l}\text { Pelaksanaan } \\
\text { Wisuda }\end{array}$ \\
\hline 30 & $\begin{array}{l}\text { Kegiatan } \\
\text { Ekstra }\end{array}$ & $\begin{array}{l}\text { Pelaksanaan } \\
\text { Ekstra }\end{array}$ \\
\hline
\end{tabular}

Dari hasil pengamataan dan identifikasi diperoleh hasil sebagai berikut :

Tabel 2

Identifikasi Cost Object, Direct Labor Cost, Direct Material Cost dan Overhead Cost

\begin{tabular}{|c|c|c|}
\hline Penetapan & Deskripsi & Keterangan \\
\hline $\begin{array}{l}\text { Cost } \\
\text { Object }\end{array}$ & $\begin{array}{l}\text { Akumulasi } \\
\text { dari } \\
\text { berbagai } \\
\text { kegiatan }\end{array}$ & Pendidikan \\
\hline $\begin{array}{l}\text { Direct } \\
\text { Labor } \\
\text { Cost }\end{array}$ & $\begin{array}{l}\text { Orang yang } \\
\text { terlibat } \\
\text { langsung } \\
\text { dalam } \\
\text { proses } \\
\text { pendidikan } \\
\text { dan } \\
\text { pengajaran }\end{array}$ & $\begin{array}{l}\text { Tenaga Pendidik } \\
\text { dan } \\
\text { Kependididkan }\end{array}$ \\
\hline $\begin{array}{l}\text { Direct } \\
\text { Material } \\
\text { Cost }\end{array}$ & $\begin{array}{l}\text { Biaya } \\
\text { bahan yang } \\
\text { langsung } \\
\text { digunakan } \\
\text { dalam } \\
\text { proses } \\
\text { pendidikan } \\
\text { dan } \\
\text { pengajaran }\end{array}$ & $\begin{array}{l}\text { Alat dan Bahan } \\
\text { Habis Pakai serta } \\
\text { Alat Tulis Kantor }\end{array}$ \\
\hline $\begin{array}{l}\text { Over Head } \\
\text { Cost }\end{array}$ & $\begin{array}{l}\text { Biaya } \\
\text { bahan baku } \\
\text { dan biaya } \\
\text { yang }\end{array}$ & $\begin{array}{l}\text { Biaya } \\
\text { pemeliharan } \\
\text { sarana dan } \\
\text { Prasarana, biaya }\end{array}$ \\
\hline
\end{tabular}




\begin{tabular}{|l|l|l|}
\hline & dikeluarkan & perjalanan dinas \\
yang tidak & dan lain-lain \\
langsung & \\
berkaitan & \\
dengan & \\
& proses & \\
pendidikan & \\
\hline
\end{tabular}

Cost object berkaitan dengan produk yang dihasilkan oleh Politeknik X, yaitu lulusan dengan jenjang pendidikan D3 yang memiliki keahlian untuk siap mengisi lowongan yang ada diperusahaan sesuai dengan kompetensi yang dimiliki. Direct Labor dan Direct Material merupakan biaya yang langsung dikeluarkan untuk menghasilkan produk. Direct Labor adalah biaya yang dikeluarkan untuk tenaga kependidikan dan pendidik dalam menghasilkan lulusan yang mempunyai kompetensi khusus. Direct Material adalah biaya yang dikeluarkan untuk bahan-bahan dan alat praktek dalam melaksanakan kegiatan belajar mengajar. Biaya tidak langsung atau Overhead Costmerupakan biaya yang dikeluarkan perguruan tinggi dalam mendukung kegiatan utama yaitu menghasilkan lulusan yang mempunyai kompetensi khusus.

Dari hasil identifikasi dan pengamatan diperoleh hasil sebagai berikut :

Tabel 3

\section{Penetapan Expense Category, Cost} Driver dan Cost Component

\begin{tabular}{|l|l|l|}
\hline Penetapan & \multicolumn{1}{|c|}{ Deskripsi } & Keterangan \\
\hline Expense & Belanja & 1. Belanja \\
Category & $\begin{array}{l}\text { untuk } \\
\text { membiayai } \\
\text { kegiatan } \\
\text { Perguruan } \\
\text { Tinggi }\end{array}$ & $\begin{array}{l}\text { 2. Belanja } \\
\text { Pengembang } \\
\text { an }\end{array}$ \\
\hline Cost Driver & $\begin{array}{l}\text { Faktor-faktor } \\
\text { yang } \\
\text { menyebabka } \\
\text { n perubahan } \\
\text { biaya } \\
\text { aktivitas }\end{array}$ & $\begin{array}{l}\text { Jumlah } \\
\text { mahasiswa, } \\
\text { jumlah } \\
\text { dosen, } \\
\text { jumlah } \\
\text { kegiatan }\end{array}$ \\
\hline Cost & Komponen & Honor tenaga \\
\hline
\end{tabular}

\begin{tabular}{|l|l|l|}
\hline Component & $\begin{array}{l}\text { anggaran } \\
\text { biaya yang } \\
\text { diserap }\end{array}$ & $\begin{array}{l}\text { kependidikan, } \\
\text { ujian, belanja } \\
\text { bahan dan } \\
\text { lainya }\end{array}$ \\
\hline
\end{tabular}

Untuk melaksanakan perancangan Model ABC di Politeknik X maka dilaksanakan tahap berikut :

1. Proses Bisnis Politeknik X

Tahap pertama yang dilakukan adalah menguraikan aktivitas yang ada di Politeknik X yang berkaitan dengan cost driver. Berikut data yang berkaitan yang diperoleh tahun 2014.

a. Jumlah Mahasiswa

Data berikuT merupakan data tahun 2014 yang diperoleh dari BAAK yang terdiri dari 3 Program Studi.

Tabel 4

Jumlah Mahasiswa Politeknik X Tahun 2014

\begin{tabular}{|l|l|c|}
\hline \multicolumn{1}{|c|}{ Program Studi } & $\begin{array}{c}\text { Jumlah } \\
\text { Mahasiswa }\end{array}$ & Presentase \\
\hline Tata Boga & 135 & $17.76 \%$ \\
\hline $\begin{array}{l}\text { Teknik } \\
\text { Elektronika }\end{array}$ & & \\
\hline $\begin{array}{c}\text { Teknik } \\
\text { Elektronika } \\
\text { Industri }\end{array}$ & 90 & $11.84 \%$ \\
\hline $\begin{array}{l}\text { Telekomun } \\
\text { ikasi }\end{array}$ & 97 & $8.02 \%$ \\
\hline $\begin{array}{l}\text { Teknik } \\
\text { Komputer } \\
\text { dan } \\
\text { Jaringan }\end{array}$ & 61 & $23.81 \%$ \\
\hline Teknik Sipil & 181 & $25.78 \%$ \\
\hline $\begin{array}{l}\text { Teknik Mesin dan } \\
\text { Alat Berat }\end{array}$ & 196 & 100 \\
\hline TOTAL & 760 & \\
\hline
\end{tabular}

b. Jumlah Dosen

Tabel 5

Jumlah Dosen dan Manjerial

\begin{tabular}{|l|l|}
\hline \multicolumn{1}{|c|}{ Program Studi } & Jumlah \\
\hline Tata Boga & 12 \\
\hline
\end{tabular}




\begin{tabular}{|l|l|}
\hline Teknik Elektronika & 19 \\
\hline Teknik Sipil & 14 \\
\hline Teknik Mesin dan & 21 \\
Alat Berat & \\
\hline
\end{tabular}

c. Jumlah Pegawai Rektorat

Jumlah pegawai yang bekerja di luar Program studi atau bekerja direktorat adalah sebanyak 43 orang.

2. Perhitungan Direct Labor Cost, Material Cost dan Overhead Cost Setelah mengidentifikasi Direct Labor Cost, Material Cost dan Overhead Cost kemudian dilanjutkan dengan perhitungan untuk menentukan besarnya biaya.

a. Perhitungan Direct Cost

Perhitungan Direct Costdengan melihat biaya dikeluarkan berkaitan dengan biaya langsung di Politeknik $X$ yang terdiri dari Gaji Dosen dan Manjerial disetiap Program Studi.

\section{Tabel 6}

Direct Labor Cost

\begin{tabular}{|l|l|l|}
\hline No & \multicolumn{1}{|c|}{ Jurusan } & Jumlah (Rp) \\
\hline 1 & Tata Boga & 282.610 .200 \\
\hline 2 & $\begin{array}{l}\text { Teknik } \\
\text { Elektronika }\end{array}$ & 443.415 .540 \\
\hline 3 & Teknik Sipil & 350.151 .024 \\
\hline 4 & $\begin{array}{l}\text { Teknik Mesin } \\
\text { dan Alat } \\
\text { Berat }\end{array}$ & 342.578 .400 \\
\hline
\end{tabular}

b. Perhitungan Direct Material Cost

Direct Material Cost berkaitan dengan jumlah biaya yang dikeluarkan untuk penggunaan bahan habis pakai disetiap program studi.

Tabel 7

Direct Material Cost

\begin{tabular}{|l|l|c|}
\hline No & \multicolumn{1}{|c|}{ Jurusan } & \multicolumn{1}{c|}{$\begin{array}{c}\text { Jumlah } \\
(\mathbf{R p})\end{array}$} \\
\hline 1 & Tata Boga & 19.472 .565 \\
\hline 2 & $\begin{array}{l}\text { Teknik } \\
\text { Elektronika }\end{array}$ & 32.377 .934 \\
\hline 3 & Teknik Sipil & 19.472 .565 \\
\hline 4 & $\begin{array}{l}\text { Teknik Mesin } \\
\text { dan Alat Berat }\end{array}$ & 32.377 .934 \\
\hline
\end{tabular}

c. Hasil Perhitungan Overhead Cost

Tabel 8

Overhead Cost

\begin{tabular}{|l|l|r|}
\hline No & \multicolumn{1}{|c|}{ Jurusan } & Jumlah (Rp) \\
\hline 1 & Tata Boga & 620.819 .379 \\
\hline 2 & $\begin{array}{l}\text { Teknik } \\
\text { Elektronika }\end{array}$ & 763.956 .739 \\
\hline 3 & Teknik Sipil & 682.968 .755 \\
\hline 4 & $\begin{array}{l}\text { Teknik Mesin } \\
\text { dan Alat } \\
\text { Berat }\end{array}$ & 1.237 .445 .109 \\
\hline
\end{tabular}

d. Hasil Perhitungan Cost Unit Per Mahasiswa

Tabel 9

Cost Unit Per Mahasiswa

\begin{tabular}{|c|c|c|}
\hline No & Jurusan & $\begin{array}{l}\text { Jumlah } \\
\text { (Rp) }\end{array}$ \\
\hline 1 & Tata Boga & $\begin{array}{r}25.825 .1 \\
52\end{array}$ \\
\hline \multirow[t]{4}{*}{2} & $\begin{array}{l}\text { Teknik } \\
\text { Elektronika }\end{array}$ & \\
\hline & $\begin{array}{ll}\text { - } & \text { Teknik } \\
& \text { Elektronik } \\
& \text { a Industri }\end{array}$ & $\begin{array}{r}24.080 .4 \\
07\end{array}$ \\
\hline & $\begin{array}{l}\text { - } \text { Teknik } \\
\text { Telekomu } \\
\text { nikasi }\end{array}$ & $\begin{array}{r}24.080 .4 \\
07\end{array}$ \\
\hline & $\begin{array}{ll}- & \text { Teknik } \\
& \text { Komputer } \\
& \text { dan } \\
& \text { Jaringan } \\
\end{array}$ & $\begin{array}{r}24.080 .4 \\
07\end{array}$ \\
\hline 3 & Teknik Sipil & $\begin{array}{r}24.799 .0 \\
28\end{array}$ \\
\hline 4 & $\begin{array}{l}\text { Teknik Mesin dan } \\
\text { Alat Berat }\end{array}$ & $\begin{array}{r}26.970 .7 \\
95\end{array}$ \\
\hline
\end{tabular}

\section{Kesimpulan}

Dari hasil analisa dapat disimpulkan Merancang Model Perhitungan biaya dengan berbasis aktivitas di Politeknik X dilakukan dengan Empat Tahap yaitu : (1) Proses Bisnis yaitu Manajerial Proses, Proses Utama dan 
Proses Pendukung, (2) Cost Object dari Politeknik X terdiri dari Empat Program Studi, (3) Mengidentifikasi Expense Kategori (4) Pembentukan Model ABC.

Perhitungan Unit Cost menggunakan metode $\mathrm{ABC}$ menghasilkan biaya satuan (unit cost) per program keahlian yakni : Program Studi Tata Boga Rp25.825.152,per tahun, Program Studi Teknik Elektro Jurusan Teknik Elektronika Industri Rp24.080.407,- per tahun. Jurusan Telekomunikasi Rp24.080.407,-- per tahun. Jurusan Teknik Komputer dan Jaringan Rp24.080.407,- per tahun, Program Studi Teknik Sipil Rp24.795.028,- per tahun. Teknik Mesin dan Alat Berat Rp26.970.795,- pertahun.

\section{Daftar Pustaka}

[1] Arikunto, Suharsimi. Prosedur Penelitian Suatu Pendekatan Praktik. Jakarta: Rineka Cipta, 2010.

[2] Bastian, Indra. Akuntansi Pendidikan, Jakarta: Erlangga, 2007.

[3] Blocher, Edward J., dkk., Manajemen Biaya. Jakarta: Salemba Empat, 2000.

[4] Bungin, Burhan. Penelitian Kualitatif : Komunikasi, Ekonomi, Kebijakan Publik, dan Ilmu Sosial Lainnya. Jakarta: Kencana Prenada Media Group, Cet.3, 2009.

[5] Carter, William K. Akuntansi Biaya. Jakarta: Salemba Empat, 2009.

[6] Departemen Pendidikan Nasional, Pengkajian Pembiayaan Pendidikan dari Masake Masa. Jakarta: Balitbang Depdiknas, 2000.

[7] Fattah, Nanang. Ekonomi dan Pembiyaan Pendidikan. Bandung: PT. RemajaRosdakarya, Cet.5, 2009.

[8] Horngren, Charles T., dkk., Akuntansi Biaya Penekanan Manajerial. Jakarta:PT.Indeks, 2008.
[9] Laporan Keuangan Tahunan 2014 Politeknik Negeri Balikpapan

[10] Maher, Michael W and Deakin, Edward B., Akuntansi Biaya. Jakarta: Erlangga,Cet.1, 1996.

[11]Mulyono. Konsep Pembiayaan Pendidikan. Jogjakarta: Ar-Ruzz Media, 2010. Panduan Perhitungan Biaya Operasional Satuan Pendidikan. Jakarta: Juni, 2011.

[12]Peraturan Pemerintah (PP) Nomor 69 Tahun 2009 yang mengatur tentang Standar

Biaya Operasi Nonpersonalia.

[13]Peraturan Pemerintah (PP) Nomor 32 Tahun 2013 Tentang Standar Nasional Pendidikan.

[14]Roztocki, Narcyz., et al., A Procedure for Smooth Implementation of Activity Based Costing in Small Companies, Proceedings of the 1999 American Societyof Engineering Management (ASEM) National Conference, 1999.

[15]Suharda, Dadang., dkk., Ekonomi dan Pembiayaan Pendidikan. Bandung: Alfabeta, 2012.

[16]Suharsaputra, Uhar. Administrasi Pendidikan. Bandung: PT. Refika Aditama, 2010.

[17]Sumarsan, Thomas. Sistem Pengendalian Manajemen: Konsep, Aplikasi dan

Pengukuran Kinerja. Jakarta: PT.Indeks, Cet.1, 2013.

[18] Wibowo, Meidi. Integrasi Proses Bisnis: Metode Peningkatan Efisisensi Perusahaan. Yogyakarta: Graha Ilmu, 2006.

[19]Zuriah, Nurul. Metodologi Penelitian Sosial dan Pendidikan (Teori - Apliaksi). Jakarta: PT. Bumi Aksara, 2007. 
